\title{
A Rare Cause of Chronic Low Back Pain
}

\author{
Ozlem Turhan Iydir ${ }^{\mathrm{a}}$, Tuba Erbilir ${ }^{\mathrm{b}}$, Didem Mercangül ${ }^{\mathrm{c}}$ \\ ${ }^{a}$ Department of Endocrinology and Metabolism, Siirt State Hospital, Siirt, Turkey \\ ${ }^{\mathrm{b}}$ Department of Physical Therapy and Rehabilitation, Siirt State Hospital, Siirt, Turkey \\ ${ }^{\mathrm{c}}$ Department of Radiology, Siirt State Hospital, Siirt, Turkey
}

\begin{abstract}
Objectives: Autosomal dominant osteopetrosis (ADO) is a rare genetic disease characterized by increased bone mass and density due to defective bone resorption. The aim of this case study is to present the clinical and radiographic features of a 22 -year-old male patient with ADO and to serve as a reminder that this rare disease should be considered in the differential diagnosis of chronic low back pain.
\end{abstract}

Materials and methods: A 22-year-old patient with ADO is presented in this case report.

Results: Clinical and radiographic features of the patient were consistent with ADO.

Conclusions: ADO should be taken into consideration in differential diagnosis of low back pain.

Keywords: Low Back Pain, osteopeotrosis

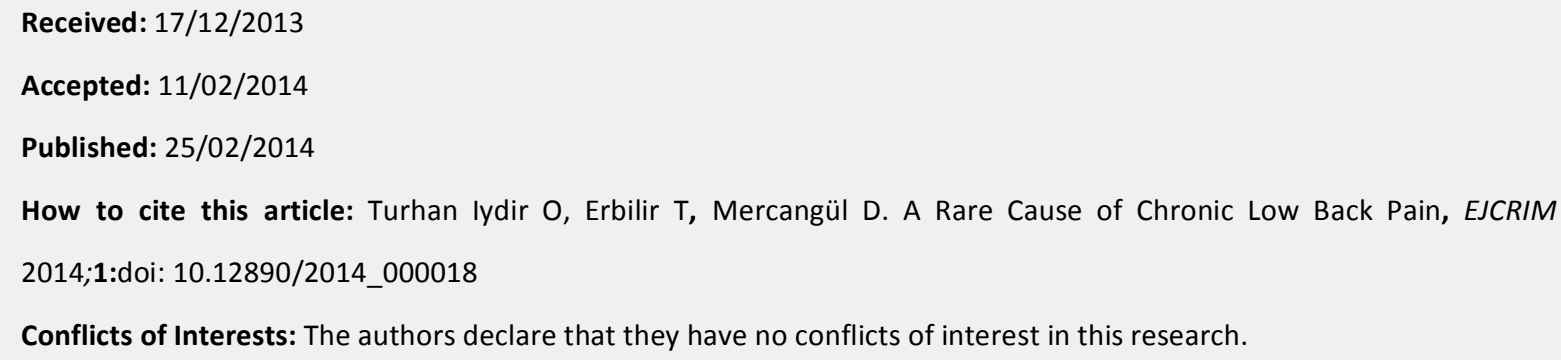




\section{European Journal \\ of Case Reports in \\ Internal Medicine}

\section{Introduction}

The osteopetroses are genetic diseases characterized by increased bone mass and density due to defective bone resorption. The bones are very dense radiographically, although they typically have increased susceptibility to fracture ${ }^{1}$. Two major forms of osteopetrosis have been described, classified on the basis of their mode of inheritance: autosomal dominant osteopetrosis (ADO, formerly known as Albers-Schönberg disease), is usually considered an adult-onset, more benign form; autosomal recessive osteopetrosis (ARO), also known as malignant infantile osteopetrosis, presents soon after birth, is often severe and leads to death if left untreated ${ }^{2}$. Here we describe a patient admitted to our outpatient clinic with low back pain and diagnosed with ADO based on clinical, laboratory and radiographic features.

\section{Case Report}

A 22-year-old man was admitted to our hospital with lower back pain he had suffered for 2 years. His pain was non-inflammatory and intermittent and was healing with analgesic use. He also reported that
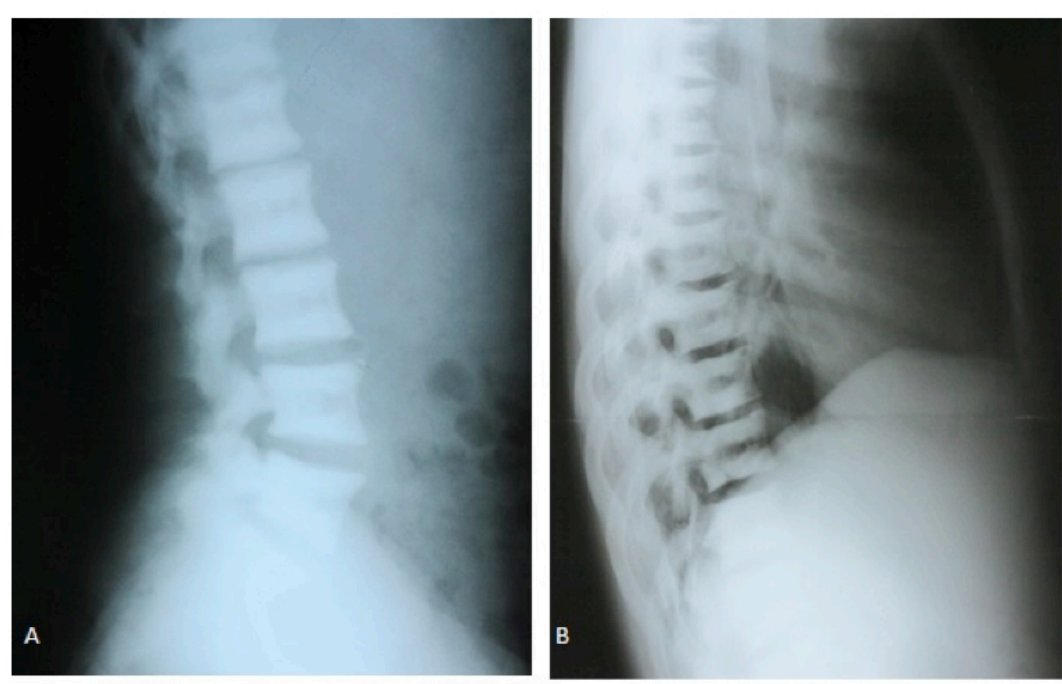

Figure 1 Lateral lumbal (A) and thoracal (B) spine graphy demonstrates "sandwich vertebra" appearance

painful at the end of movement. The other joints were normal. Lumbar Schober, chest expansion and fingertip-to-floor were found to be 4,4 and $40 \mathrm{~cm}$, respectively.

Physical examination showed other systems were normal and psychomotor development was also normal. A plain radiograph of the spine showed end-plate thickening and sclerosis producing the classic "sandwich vertebra" appearance (Figs.1,2). his pain had worsened after his military service and had become continuous. His history was normal; he had no history of any fracture or chronic drug use. There was no parental consanguinity.

The patient was $161 \mathrm{~cm}$ tall and he weighed $60 \mathrm{~kg}$. Movements of his waist were free in all directions, but dorsal and lumbar spine were

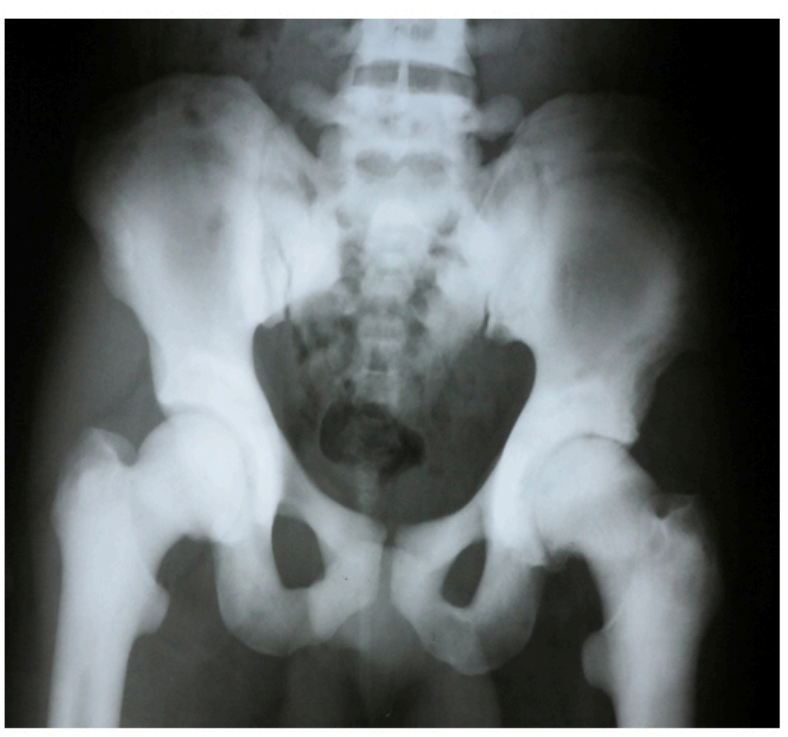

Figure 2 AP pelvis graphy demonstrates diffuse sclerotic pelvic bones 
There was a fracture at the waist of the scaphoid on posteroanterior plain radiograph of the wrist. Biochemical analyses of the patient were within normal limits. There were no abnormalities in his complete blood count or peripheral blood smear. The other biochemical parameters were as follows: parathyroid hormone $32.8 \mathrm{pg} / \mathrm{ml}(11.1-79.5 \mathrm{pg} / \mathrm{ml})$, alkaline phosphatase $68 \mathrm{U} / \mathrm{l}(50-136 \mathrm{U} / \mathrm{l})$, 25-OH-D3 $22.3 \mathrm{ng} / \mathrm{ml}(10-250 \mathrm{ng} / \mathrm{ml}$ ), serum calcium $10.1 \mathrm{mg} / \mathrm{dl}$ and serum phosphorus $2.7 \mathrm{mg} / \mathrm{dl}$. Creatinine clearance was normal. His liver, spleen and both kidneys were sonographically normal. Bone mineral density L1-L4 T score was 11.3 and Z score was 11.3. The existing clinical, radiological and laboratory findings indicated osteopetrosis type 2 .

\section{Discussion}

Osteopetrosis is described as a heterogeneous group of diseases related to defective bone resorption ${ }^{3}$. Although patients with ADO have typical and prevalent symptoms, they are often diagnosed by chance. The typical findings are increased fracture frequency, delayed healing and osteomyelitis, especially in the jaw ${ }^{4}$. On the lateral radiographs of the thoracic and lumbar spine, radiolucent regions of increased opacity at the superior and inferior margins of the vertebral bodies are detected; they have also been called Rugger Jersey Spine Signs (RJSS). Some disease processes may mimic RJSS such as Paget's disease, metastatic lesions, osteoporosis, osteomalacia or renal osteodystrophy ${ }^{1}$. Fractures occur in about $80 \%$ of cases and these commonly occur in the femur ${ }^{5}$. Our patient had lower back pain and a scaphoid fracture, which was diagnosed on plain radiograph of his wrist. Our patient shows that it is important to keep this rare clinical entity in mind in differential diagnosis of chronic low back pain.

\section{Learning points:}

- Autosomal dominant osteopetrosis is a rare disease often diagnosed by chance.

- Typical findings of autosomal dominant osteopetrosis are 'sandwich' vertebra appearance, so-called Rugger Jersey Spine Sign and 'bone within bone' appearance in the iliac bone.

- Autosomal dominant osteopetrosis should be taken into consideration in differential diagnosis of low back pain.

\section{REFERENCES}

1. Stark Z, Savarirayan R. Osteopetrosis, Orphanet J Rare Dis 2009;4:5.

2. Sobacchi C, Schulz A, Coxon FP, Villa A, Helfrich MH. Osteopetrosis: genetics, treatment and new insights into osteoclast function, Nat Rev Endocrinol 2013;9:522-536.

3. Johnston CC Jr., Lavy N, Lord T, Vellios F, Merritt AD, Deiss WP, Jr. Osteopetrosis. A clinical, genetic, metabolic, and morphologic study of the dominantly inherited, benign form. Medicine

1968;47:149-67. 


\section{European Journal \\ of Case Reports in \\ Internal Medicine}

4. Bollerslev J, Henriksen K, Frost Nielsen M, Brixen K, Van Hul W. Autosomal dominant osteopetrosis revisited: lessons from recent studies. Eur J Endocrinol 2013;169:R39-57.

5. De Vernejoul MC. Sclerosing bone disorders. Best Pract Res Clin Rheumatol 2008;22:71-83. 